\title{
$X$-ray photoelectron spectroscopy of oxygen adsorbates on Al(111): Theory experiment
}

\author{
P. S. Bagus, F. Parmigiani, G. Polzonetti, F. Illas, and C. R. Brundle \\ IBM Research Division, Almaden Research Center, 650 Harry Road, San Jose, California 95120-6099
}

(Received 10 October 1990; accepted 24 December 1990)

\begin{abstract}
We present the result of polar angle resolved $\mathrm{x}$-ray photoemission spectroscopy on $\mathrm{Al}(111) / \mathrm{O}$ and cluster calculations of the $\mathrm{O}(1 s)$ binding energy (BE) for various model situations. In the experimental data two $\mathrm{O}(1 s)$ peaks are observed, separated by $1.3 \mathrm{eV}$. The angular behavior (depth-resolution) could indicate that the lower BE peak is associated with an $O$ atom under the surface, and the higher $\mathrm{BE}$ peak with an $\mathrm{O}$ atom above the surface. Equally, it could indicate oxygen islands on the surface where the perimeter atoms have a higher $O(1 s) \mathrm{BE}$ than the interior atoms. The cluster calculations show that the former interpretation cannot be correct, since an $O$ ads below the surface has a higher calculated $\mathrm{O}(1 \mathrm{~s}) \mathrm{BE}$ than one above. Cluster calculations simulating oxygen islands are, however, consistent with the experimental data.
\end{abstract}

\section{INTRODUCTION}

The $\mathrm{Al}(111) / \mathrm{O}$ system has been extensively studied in the past ${ }^{1-4}$ and until a recent scanning tunnel microscope (STM) study the accepted picture was that two $\mathrm{O}$ adsorbate species existed, one above and one below the surface. The STM study indicated that only small, close-packed $(1 \times 1) \mathrm{O}$ islands existed prior to formation of oxide on flat (111) terraces.

In the present work, we report the $\mathrm{x}$-ray photoemission spectroscopy (XPS) O(1s) spectrum in the chemisorption regime at room temperature as a function of electron detection angle, which varies the degree of surface sensitivity. We have also performed $a b$ initio electronic structure calculations on $\mathrm{Al}_{14}$ clusters with oxygen adatoms and small islands in various configurations. $\mathrm{O}(1 s) \mathrm{BE}$ are derived from these calculations with the framework of Koopmans' theorem. ${ }^{6}$

\section{RESULTS AND DISCUSSION}

The XPS data were taken on a previously described instrument using a AlK $\alpha$ source. ${ }^{7}$ Takeoff angles of $10^{\circ}$ and $80^{\circ}$ were used to strongly vary the degree of surface sensitivity of the measurement. The sample was a single crystal Al(111) surface oriented to within $0.6^{\circ}$. The oxygen coverage in this work (room temperature exposure) was $\sim 0.3$ monolayer, based on relative $\mathrm{Al}(2 p) / \mathrm{O}(1 s)$ intensities and theoretical photoionization cross-sections. ${ }^{8}$ No oxide species were present, as judged by the lack of any $2.7 \mathrm{eV}$ chemically shifted $\mathrm{Al}(2 p)$ component [ which is known to represent $\mathrm{Al}_{2} \mathrm{O}_{2}$ (Ref 9.)] even at $10^{\circ}$ takeoff angle.

Figure 1 shows the $\mathrm{Al}(2 p)$ and $\mathrm{O}(1 s)$ spectra for the clean surface and after oxygen exposure. The main point to notice is that the ratio of the $533.5 / 532.1 \mathrm{eV}$ peaks increases at low takeoff angle. An obvious explanation for this would be that the $533.5 \mathrm{eV}$ peak represents an oxygen adatom on the surface and the $532.1 \mathrm{eV}$ peak one below the surface. The cluster calculations, however, show that this cannot be the case because it is always found, independent of the size of the Al substrate cluster and the exact site of an $\mathrm{O}$ adatom, that an $\mathrm{O}$ adatom beneath the surface has a significantly higher $\mathrm{O}(1 s)$ $\mathrm{BE}$ than one above. For example, a $\mathrm{Al}_{14} \mathrm{O}$ cluster, one of those calculated is shown in Fig. 2 with the $\mathrm{O}$ adatom in its calculated equilibrium position $0.66 \AA$ above the surface. The calculated $\mathrm{O}(1 \mathrm{~s}) \mathrm{BE}$ (Koopmans' theorem value) is $560.6 \mathrm{eV}$ in this position. The equivalent value where the $\mathrm{O}$ atom is moved below the plane of the surface to a new equilibrium position ( $1.17 \AA$ below the surface) is $562.5 \mathrm{eV}, 1.9$ $\mathrm{eV}$ higher. Performing $\mathrm{O}(1 s)$ hole-state calculations to include final-state screening reduces the absolute numbers by $\sim 25 \mathrm{eV}$, bringing them close to the experimental $\mathrm{O}(1 \mathrm{~s}) \mathrm{val}$ ues, but does not change the ordering; i.e., an $\mathrm{O}$ atom below the surface still has a significantly higher $\mathrm{O}(1 s) \mathrm{BE}$ than one above.

Since the idea that the two $\mathrm{O}(1 \mathrm{~s})$ peaks represent $\mathrm{O}$ adsorbates above and below the surface was inconsistent with the $\mathrm{BE}$ calculations, we redid the calculations for a number of oxygen clusters designed to simulate a small $O$ adsorbate island on an $\mathrm{Al}(111)$ surface where perimeter $\mathrm{O}$ atoms have
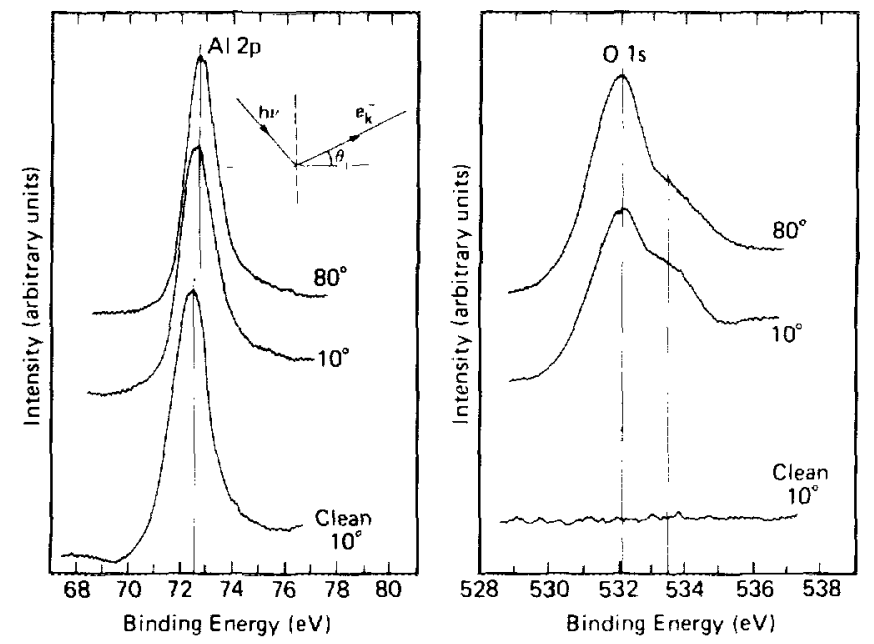

FIG. 1. $\mathrm{Al}(2 p)$ and $\mathrm{O}(1 s)$ spectra for a clean $\mathrm{Al}(111)$ surface and after adsorption to $\sim 0.3 \mathrm{~mL} \mathrm{O}$. Data at two emission angles, $80^{\circ}$ (near normal emission) and at $10^{\circ}$ (near grazing emission) are shown. 

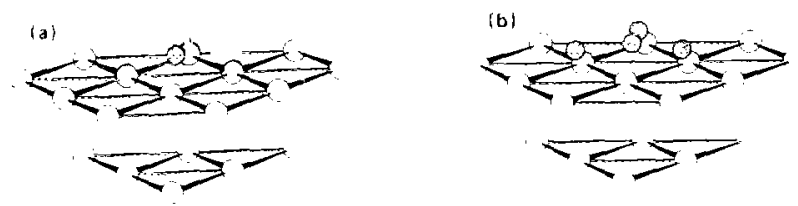

Fig. 2. (a) Sideview of an $\mathrm{Al}_{1,} \mathrm{O}$ cluster. The $\mathrm{Al}$ ( 111 ) surface is represented by 12 atoms, the second layer by six atoms, and the third by one atom below the central adsorption site of the $\mathrm{O}$ adatom. (b) As Fig. 2(a) except for an $\mathrm{Al}_{1}, \mathrm{O}_{4}$ cluster with the $\mathrm{O}$ adatoms in adjacent threefold sites.

a lower number of $\mathrm{O}$ atom neighbors than interior $\mathrm{O}$ atoms. $\mathrm{An} \mathrm{O}_{4}$ cluster of this type is shown in Fig. 2(b). The central oxygen is in the same position as the $\mathrm{O}$ adsorbate of Fig. 2 (a), but additional atoms have been added at adjacent threefold adsorption sites. The $\mathrm{O}-\mathrm{O}$ adsorption distance here is very short ( 0.6 that found in the STM study $)^{5}$ so any differential effect between central and perimeter $O$ atom, due to a change in $\mathrm{O}$ atom coordination, might be expected to be maximized. The calculated $\mathrm{O}(1 s)$ BEs are $557.3 \mathrm{eV}$ (central) and $558.7 \mathrm{eV}$ (perimeter). Thus, there is a $1.4 \mathrm{eV}$ higher $\mathrm{O}(1 s) \mathrm{BE}$ for the perimeter $\mathrm{O}$. This separation of $\mathrm{BEs}$ is consistent with the experimental BE difference, but an explanation in terms of $O$ islands requires a reason why the $O(1 s)$ intensity of the perimeter atoms should increase relative to that of interior atoms as one moves from normal to grazing angle emission. This is in fact, to be expected since, on average, photoelectrons ejected, at grazing emission, from perimeter $O$ atoms will suffer less effect of inelastic scattering with other $\mathrm{O}$ atoms than will photoelectrons ejected from interior $\mathrm{O}$ atoms. The self-attenuation of the $\mathrm{O}(1 \mathrm{~s})$ signal at grazing angle emission is thus less for perimeter atoms and the $\mathrm{O}(1 s)$ intensity ratio of perimeter to interior atoms will therefore increase as one moves to grazing angle.

\section{CONCLUSIONS}

On the basis of the $\mathrm{O}_{4}$ cluster calculation, then, we are drawn to the conclusion that the higher $\mathrm{O}(1 s) \mathrm{BE}$ experimental peak represents perimeter atoms in small $\mathrm{O}$ islands, in agreement with the STM results. Performing calculations on different $\mathrm{O}$ clusters (number of $\mathrm{O}$ atoms, $\mathrm{O}-\mathrm{O}$ spacing) does not change this conclusion, through the calculated $\mathrm{BE}$ difference does vary from the $1.4 \mathrm{eV}$ value found for the $\mathrm{O}_{4}$ cluster ${ }^{10}$ On the basis of the present results we suggests that a reassignment of the vibrational spectra, (obtained by highresolution electron-energy-loss spectroscopy $)^{2-4}$ in terms of oxygen islands be considered. It was largely the interpretation of a particular vibrational frequency that led to the ideas of the coexistence of surface and subsurface $O$ adsorbate species. In addition, the $O(1 s)$ spectra during oxygen adsorption on surfaces known to form islands should be reexamined to look for similar effects.

'I. P. Batra and L. Kleinman, J. Electron. Spectrosc. Relat. Phenom. 33, 175 (1984).

${ }^{2}$ R. L. Strong, B. Furney, F. W. deWette, and J. L. Erskine, J. Electron. Spectrosc. Relat. Phenom. 29, 187 (1983)

'J. E. Crowell, J. G. Chen, and J. T. Yates, Surf. Sci. 165, 37 (1986)

${ }^{+}$C. Astaldi, P. Geng, and K. Jacobi, J. Electron. Spectrosc. Relat. Phenom. 44. 175 (1987)

'J. Wintterlin, H. Bruce, H. Hofer, and R. J. Behm, Appl. Phys. A. 47, 99 (1988)

"T. Koopmans, Physics I 106, (1933).

${ }^{7}$ C. R. Brundle, IBM J. Res. Dev. 22, 235 (1978).

${ }^{x}$ J. H. Scofield, J. Electron. Spectrosc. Relat. Phenom. 8, 129 (1976).

"C. F. McConville, D. L. Seymour, D. P. Woodruff, and S. Bao, Surf. Sci 188, 1 (1987).

"F. Parmigiani, G. Polzonetti, F. Illas, P. S. Bagus, and C. R. Brundle, Phys. Rev. B (submitted) 